\title{
Affect and mathematics in young children. An introduction
}

Sophie Batchelor ${ }^{1}$, Joke Torbeyns ${ }^{2}$ and Lieven Verschaffe ${ }^{2}$

${ }^{1}$ Mathematics Education Centre, Loughborough University, Loughborough, Leicestershire,

$$
\text { LE11 3TU, UK }
$$

${ }^{2}$ Center for Instructional Psychology and Technology, Katholieke Universiteit Leuven, Dekenstraat 2, Post Box 3773, B-3000, Leuven, Belgium

Address for correspondence:

Prof. Dr. Lieven Verschaffel

Center for Instructional Psychology and Technology

Katholieke Universiteit Leuven

Dekenstraat 2

Post Box 3773

B-3000 Leuven

Belgium

Tel: $0032(0) 16326258$

Email: lieven.verschaffel@kuleuven.be 


\begin{abstract}
Mathematics-related affect comprises an individual's attitudes, beliefs, emotions and motivations towards mathematics. These affective constructs have been widely studied in mathematics education and cognitive psychology and have been shown to be related to cognitive outcomes such as performance on a range of mathematical tasks. However, it is not yet clear how these constructs develop, or how they relate to cognitive factors in young children who are in the early stages of learning mathematics. As such, the current special issue focuses on mathematics-related affect in primary school children aged 4 to 10 years. It brings together five recent empirical studies and two discussant articles looking at the development of attitudes, beliefs, emotions and motivations towards mathematics, and the relations between affective and cognitive factors in these young age groups. In this introductory paper we provide some brief historical context, followed by a rationale for the special issue, and an overview of its structure and scope.
\end{abstract}


It is widely acknowledged that the development of expertise in a particular field depends not only on cognitive skills, but also on the attitudes, beliefs, emotions and motivations of the learner. These dispositions or affective factors may to some extent be predisposed, but also influenced by the learning environment, and thus they have been a topic of growing interest in education (Linnenbrink 2006). This is noticeably the case in the domain of mathematics (e.g., Zan, Brown, Evans, \& Hannula 2006), likely because mathematics is a subject which is typically perceived to evoke strong and often negative reactions (Dowker, Sarkar, \& Looi 2016).

A wealth of studies from mathematics education and cognitive psychology have advanced our theoretical frameworks and methodological tools for studying affect in mathematics (see, for example, Hannula et al. 2016, for a recent overview of the field). However, studies have tended to focus on older children and adults. It is not yet clear how attitudes, beliefs, emotions and motivations towards mathematics develop, and how they might interact with cognitive factors in the preschool and early primary school years. This special issue brings together five recent empirical studies and two discussant articles that focus on the development of, and interactions between, affective and cognitive factors in these young age groups. Together, the contributions cover a range of affective components, giving us complementary insights into children's emerging dispositions towards mathematics and the relations between affective and cognitive factors.

In this introduction we first provide some brief historical perspectives with an overview of the theories and methods developed for studying affect in mathematics. Next, we consider the importance of studying affect in young children who are in the early stages of acquiring formal mathematical skills. We discuss the challenges associated with studying such young age groups and the current state of research. Finally, we outline the scope and structure of the special issue. 


\section{Affect and mathematics: Historical context}

Research into the affective aspects of learning mathematics can be seen to date back to studies on mathematics anxiety and attitudes to mathematics in the early 1960's, and it has evolved considerably in the last 60 years (Dowker et al. 2016; Goldin 2009; Goldin, Röskin, \& Törner 2009; McLeod 1994; Zan et al. 2006). At present, the field of affect is perhaps best characterised by the richness and diversity of its theories and concepts. The term 'affect' has been defined in many ways, both within mathematics education and more generally within education and psychology (see, for example, Malmivuori 2001, for a review of definitions in the affective domain). In its narrowest sense it is used to refer to a person's feelings and emotions (e.g. Anderson 1981; Mandler 1989), while in its broadest sense it is used as an umbrella term to describe a whole host of variables that are not purely cognitive, encompassing also attitudes, beliefs, and motivations (e.g. Zan et al. 2006).

With a growing number of studies on a wide array of affective constructs, there have been increasing concerns over poorly defined variables and "fuzzy" definitions. The need to clarify and consolidate concepts and theoretical frameworks has dominated much of the literature since the late 1980's (Fennema 1989; Hart 1989; McLeod 1989; McLeod \& Adams 1989). Several publications including a special issue on affect in mathematics education published in Educational Studies in Mathematics in 2006 (Zan et al. 2006) demonstrate that conceptual clarification has been (and remains) a primary focus. Here we will not attempt an in-depth review of the debates around conceptual clarification, but we will give an overview of the key developments and main constructs in the field in order to put the contributions to the current special issue in context. 
Early studies on mathematics-related affect drew on psychological theories and methods that used a quantitative approach to measure attitudes and anxiety. The 1960's and 1970's saw the development of a number of Likert scale questionnaires, most notably the Mathematics Anxiety Rating Scale (MARS; Richardson \& Suinn 1972) and the Mathematics Attitude Scales (Fennema \& Sherman 1976). These were used widely to look at the relations between affect and performance and to explore gender differences in mathematical outcomes (see Hembree 1990; Hyde, Fennema, Ryan, Frost, \& Hopp 1990; and Ma \& Kishor 1997, for reviews). As the research grew and the array of measurement tools expanded, there was a shift towards seeing attitudes and anxiety as multidimensional affective constructs (Aiken 1974), rather than unidimensional variables that could be assessed with a single measurement scale. For example, the Mathematics Attitude Scales (Fennema \& Sherman 1976) comprised nine separate subscales measuring: attitudes towards success in mathematics; beliefs about mathematics as a male domain; perceptions of mother, father and teacher interest, encouragement and confidence in one's mathematics ability; confidence in mathematics; mathematics anxiety; motivation; and beliefs about the usefulness of mathematics.

\section{A reconceptualization of mathematics-related affect}

In the 1980's, the traditional measurement approach to attitude research became increasingly criticised for its lack of a strong theoretical basis (e.g. McCleod \& Adams 1989). There were concerns that researchers were defining affective constructs merely by the questionnaires used in their research (e.g., Leder 1985), and that neither the relationships among affective constructs, nor the mechanisms through which they play a role in the mathematics classroom were clear (e.g., McLeod 1988). There was a move towards using more qualitative research 
methods such as observations and interviews to gain a richer understanding of the interplay of affective factors in real life mathematical learning situations. This research largely came from socio-cultural and socio-constructivist perspectives and centred on mathematical problem-solving activities. It opened several new avenues of research in mathematics-related affect with questions around metacognition, beliefs about mathematics and motivational aspects such as students' self-efficacy (e.g., Garafalo 1989; Garofalo \& Lester 1985; Lester, Garofalo, \& Kroll 1989; McLeod 1988; Schoenfeld 1989; Silver 1985).

The publication of the book 'Affect and Mathematical Problem Solving: A New Perspective' (McLeod \& Adams 1989) marked a turning point in the field of mathematicsrelated affect, and this was shortly followed by a new theoretical framework for research in the affective domain (McLeod 1992). As described by Di Martino (this issue), McLeod categorised affect into three main constructs: beliefs, attitudes and emotions, which vary in their stability and intensity. All three aspects of affect are considered in the current special issue, with the addition of motivations, a lesser studied construct in mathematics education, but one which has been widely investigated within education and psychology more generally.

According to McLeod's (1992) conceptualisation, beliefs are the most stable, least intense of the affective constructs. Research into beliefs has included beliefs about mathematics as a subject, beliefs about oneself in relation to mathematics, beliefs about mathematics teaching and beliefs about the social context (see, for example, Leder, Pehkonen, \& Törner 2002). In contrast to beliefs, emotions are considered the least stable, most intense aspect of affect, and they are harder to study given their changeable nature. Closely tied to beliefs and emotions are attitudes which McLeod (1992) defines as "positive or negative feelings of moderate intensity and reasonable stability" (p. 581). Attitudes are a somewhat controversial aspect of McLeod's framework as they are often defined as consisting of beliefs and emotions (Hannula et al. 2016). Finally, motivational aspects have 
been shown to be related to emotional experiences and include constructs such as interest, persistence and self-efficacy (e.g., Berhenke, Miller, Brown, Seifer, \& Dickstein 2011; Pekrun, Goetz, Titz, \& Perry 2002).

Beliefs, attitudes and motivations have largely been measured through traditional methods such as self-reports and questionnaires, although there are exceptions that have used qualitative interviews and narrative methods, particularly for the measurement of beliefs (see, for example, Di Martino, this issue). The measurement of emotions can be seen to have involved a wider variety of methods. Emotions have often been investigated in the context of problem solving (e.g., the "Aha!" experience (Liljedahl 2004)), and they have been measured both qualitatively through interviews (e.g., Hannula 2002; Op’t Eynde, De Corte, \& Verschaffel 2006) and quantitatively through questionnaires and physiological measures such as heart rate, skin conductance and cortisol secretion (Dew, Galassi, \& Galassi 1984; Mattarella-Micke, Mateo, Kozak, Foster, \& Beilock 2011). In the next section, we consider these affective variables in relation to young children's mathematics-related affect.

\section{Affect and mathematics in young children}

Research on affect in mathematics has mainly focused on older children and adults, with several studies showing that affective factors are related to mathematics achievement, and that attitudes towards mathematics decline throughout the late primary and secondary school years (Hernandez-Martinez \& Pampaka 2017; Ma \& Kishor 1997; Wigfield \& Meece 1988). It is only in the last decade or so that the importance of early mathematical outcomes has become increasingly recognised and researchers have started to develop tools for measuring affective constructs in young children. The literature on attitudes to mathematics and mathematics anxiety has been particularly rife with new questionnaire-based measures (see, for example, Table 1 in Ganley \& McGraw 2006, for a summary of mathematics anxiety 
measures for primary school aged children). Petronzi, Staples, Sheffield, Hunt and FittonWilde (this issue) add to these new measures with a pictorial mathematics anxiety scale for children as young as 4 years.

Although there are now many self-reports for measuring young children's attitudes to mathematics and mathematics anxiety, it is not yet clear how these attitudes and emotions develop, and how they relate to concurrent and future mathematical skills. Some studies have found an association between young children's mathematics anxiety and their mathematics performance (Ramirez, Gunderson, Levine, \& Beilock 2013; Vukovic, Keiffer, Bailey, \& Harari 2013; Wu, Barth, Amin, Malcarne, \& Menon 2012), whilst others have not (Dowker, Bennett, \& Smith 2012; Haase et al. 2012; Hill et al. 2016; Krinzinger, Kaufmann, \& Willmes 2009). As such, researchers are continuing to explore the interplay between attitudes, emotions and performance in young children (e.g., Dowker, Cheriton, Horton, \& Mark, this issue; Passolunghi, Cargnelutti, \& Pellizzoni, this issue; Petronzi et al., this issue). There are efforts to uncover the relations between different attitudinal components (e.g., Dowker et al., this issue; Jameson 2014) as well as the links with domain general and domain specific cognitive skills (Cargnelutti, Tomasetto, \& Passolunghi 2017a; Passolunghi et al., this issue; Wu et al. 2017). Within this literature, some researchers conceptualise mathematics anxiety as an attitude (e.g., Dowker et al, this issue) focusing largely on the cognitive aspects of anxiety such as the worrisome thoughts. Others conceptualise mathematics anxiety as an emotional factor, focusing more on the behavioural reactions (e.g., mathematics avoidance) and physiological responses (e.g., increased heart rate) (e.g., Passolunghi et al., this issue). The different foci within measures of mathematics anxiety may help to explain the currently mixed findings in the field (Dowker et al. 2016).

There are of course some challenges associated with measuring affective constructs in young children. Questionnaire-based measures have to be carefully constructed to ensure 
they are age appropriate, and even then, very young children may struggle to provide reliable self-reports. Moreover, questionnaires do not provide in depth information about how attitudes, beliefs, emotions and motivations manifest in a mathematical learning or performance situation. They tend to be trait-based measures rather than state-based measures. Some researchers have preferred to use indirect measures such as teacher ratings of children's motivations (e.g., Lepola \& Hannula-Sormunen, this issue). Other researchers have used creative interviewing techniques and narratives to gain insights into primary school children's beliefs about mathematics (e.g., Di Martino, this issue; McDonough \& Sullivan 2014). This special issue presents a variety of methods which can be taken forward and further developed to advance our methodological tools for studying affect in young children. Given the varied and complex nature of the affective domain, it is likely that a combination of methods is needed to help us understand how different affective constructs interact, and how they relate to mathematical development in this age group.

\section{Overview of the special issue}

Several studies have shown significant and long-lasting effects of early mathematical outcomes on later mathematical success (e.g., Duncan et al. 2007; Jordan, Kaplan, Ramineni, \& Locuniak 2009; Reeve, Reynolds, Humberstone, \& Butterworth 2012). As such, there has been a growing body of research into the cognitive foundations of mathematics (e.g., RittleJohnson \& Jordan 2016). Research with older children and adults has demonstrated that affective factors are associated with cognitive outcomes, thus a better understanding of the development of young children's attitudes, beliefs, emotions and motivations towards mathematics may help us to foster early mathematical skills.

This special issue aims to shed light on the current state of research on young children's mathematics-related affect and its relation with cognitive outcomes. It seeks to 
complement the previous special issue on affect in mathematics education published in Educational Studies in Mathematics in 2006 (Zan et al. 2006), which compared different theoretical frameworks for studying affect without specific attention to measurement issues, relations with mathematics performance, or the early years of mathematics education. The five empirical contributions include samples of children ranging 4-10 years, each paper focusing on one or two of the affective constructs identified above.

In the first contribution, Dowker et al. investigate attitudes to mathematics in English and Chinese first graders, aged 6 years. They focus on four attitudinal components, namely children's mathematics anxiety, liking for mathematics, unhappiness at poor performance in mathematics and self-rating in mathematics. By examining both their interrelations and their associations with mathematical performance they deepen our understanding of the key attitudes that may be important for early success in mathematics. Moreover, comparisons between the Chinese and English samples provide novel insights into the interplay of affective factors in young children in different educational settings.

The second contribution of Petronzi et al. focuses specifically on mathematics anxiety, one of the most prominently studied aspects of math-related attitudes and emotions. Petronzi et al. report on the development of the Children's Mathematics Anxiety Scale - UK (CMAS-UK), a new pictorial Likert-scale questionnaire for children aged 4 to 7 years. In developing and validating the CMAS-UK they extend the available tools for measuring mathematics anxiety in the first years of school, and they further our understanding of the interplay between anxiety and performance in early years mathematics education.

In the third contribution, Lepola and Hannula-Sormunen present a longitudinal study of 6- to 8-year-old children's motivational orientations, domain specific attention to number (i.e. spontaneous focusing on numerosity; SFON) and arithmetical skills. They shed light on the developmental relations between these variables, deepening our understanding of the 
direction of the associations between affect (motivations) and early mathematical outcomes. Their use of teacher ratings of affect, rather than direct child assessments or self-reports, is unique to this special issue contribution and it offers a complementary tool for researchers to consider using when working with particularly young age groups.

In the fourth contribution, Passolunghi et al. address the role of mathematics anxiety on a specific aspect of mathematics achievement, that is arithmetical problem-solving skills. Their sample consists of 10-year-old children, the eldest age group considered in this special issue, and they include measures of domain general cognitive skills (processing speed and working memory) as well as domain specific mathematical skills. The inclusion of these domain general skills, which have been shown to be important for mathematics learning and performance, helps to build a broader picture of the interplay between affect and cognition within this special issue and opens several avenues for future research.

The fifth contribution of Di Martino provides an in-depth qualitative analysis of primary school children's views of mathematical problems. It complements the previous contributions not only in its methodology (qualitative rather than quantitative), but also in terms of its theoretical scope and the sample of children studied. Using a three-dimensional framework of attitudes, beliefs and emotions, Di Martino examines, cross-sectionally, the evolution of children's characterization of a 'problem' from kindergarten to the end of primary school. In doing so, he offers richer descriptive information on the development of math-related affect across the whole age range of children covered in this special issue.

The five empirical studies are followed by two discussion papers, the first from Markku Hannula, a specialist in mathematics-related affect, and the second from Andreas Obersteiner, a specialist in the mathematical learning of young children. In their discussion articles, Hannula and Obersteiner reflect on the critical issues and findings in the different contributions, the educational relevance and the potential directions for future research. 


\section{Note}

The initiative for this special issue grew out of a workshop entitled "Beyond the cognitive side of expertise", October 12-14, 2016, Irish College Leuven, organized by the Scientific Research Community: WO.008.14N 'Developing competencies in learners: From ascertaining to intervening", of which the University of Leuven is coordinator, and sponsored by the Fund for Scientific Research-Flanders. However, the specific themes addressed in the special issue and the authors involved coincide only partially with those involved in that workshop.

\section{References}

Aiken, L. (1974). Two scales of attitude toward mathematics. Journal for Research in Mathematics Education, 5, 67-71. doi:10.2307/748616

Anderson, L.W. (1981). Assessing affective characteristics in the schools. Boston: Allyn and Bacon.

Berhenke, A., Miller, A. L., Brown, E., Seifer, R., \& Dickstein, S. (2011). Observed emotional and behavioral indicators of motivation predict school readiness in Head Start graduates. Early Childhood Research Quarterly, 26, 430-441. doi:10.1016/j.ecresq.2011.04.001

Cargnelutti, E., Tomasetto, C., \& Passolunghi, M. C. (2017a). The interplay between affective and cognitive factors in shaping early proficiency in mathematics. Trends in Neuroscience and Education, 8-9, 28-36. doi:10.1016/j.tine.2017.10.002 
Dew, K. M. H., Galassi, J., \& Galassi, M. D. (1984). Math anxiety: Relation with situational test anxiety, performance, physiological arousal, and math avoidance behavior. Journal of Counseling Psychology, 31, 580-583. doi:10.1037/0022-0167.31.4.580

Dowker, A., Bennett, K., \& Smith, L. (2012). Attitudes to mathematics in primary school children. Child Development Research, 2012:124939. doi:10.1155/2012/124939

Dowker, A., Sarkar, A., \& Looi, C. Y. (2016). Mathematics anxiety: What have we learned in 60 years? Frontiers in Psychology, 7:508. doi:10.3389/fpsyg.2016.00508

Duncan, G. J., Dowsett, C. J., Claessens, A., Magnuson, K., Huston, A. C., Klebanov, P., ... \& Japel, C. (2007). School readiness and later achievement. Developmental Psychology, 43, 1428-1446. doi:10.1037/0012-1649.43.6.1428

Fennema, E. (1989). The study of affect and mathematics: A proposed generic model for research. In D. B. McLeod \& V. M. Adams (Eds.), Affect and mathematical problem solving. A new perspective (pp. 205-219). New York: Springer-Verlag.

Fennema, E., \& Sherman, J. A. (1976). Fennema-Sherman Mathematics Attitude Scales: Instruments designed to measure attitudes toward the learning of mathematics by females and males. Journal for Research in Mathematics Education, 7, 324-326. doi:10.2307/748467

Ganley, C. M., \& McGraw, A. L. (2016). The development and validation of a revised version of the math anxiety scale for young children. Frontiers in Psychology, 7, 1181. doi:10.3389/fpsyg.2016.01181

Garofalo, J. (1989). Beliefs and their influence on mathematical performances. Mathematics Teacher, 82, 502-505. 
Garofalo, J., \& Lester, F. K., Jr. (1985). Metacognition, cognitive monitoring, and mathematical performance. Journal for Research in Mathematics Education, 16, 163 176. doi:10.2307/748391

Goldin, G. A. (2009). The affective domain and students' mathematical inventiveness. In R. Leikin, A. Berman, \& B. Koichu (Eds.), Creativity in Mathematics and the Education of Gifted Students (pp. 181-194). Rotterdam: Sense Publishers.

Goldin, G. A., Rösken, B., \& Törner, G. (2009). Beliefs - No longer a hidden variable in mathematics teaching and learning processes. In J. Maass \& W. Schlöglmann (Eds.), Beliefs and Attitudes in Mathematics Education: New Research Results (pp. 1-18). Rotterdam: Sense Publishers.

Haase, V. G., Júlio-Costa, A., Pinheiro-Chagas, P., Oliveira, L. D. F. S., Micheli, L. R., \& Wood, G. (2012). Math self-assessment, but not negative feelings, predicts mathematics performance of elementary school children. Child Development Research, 2012:982672. doi:10.1155/2012/982672

Hannula, M. S. (2002). Attitude towards mathematics: Emotions, expectations and values. Educational studies in Mathematics, 49, 25-46. doi:10.1023/A:1016048823497

Hannula, M. S., Di Martino, P., Pantziara, M., Zhang, Q., Morselli, F., Heyd-Metzuyanim, E., ... \& Goldin, G. A. (2016) Attitudes, beliefs, motivation, and identity in mathematics education. In Attitudes, Beliefs, Motivation and Identity in Mathematics Education. ICME-13 Topical Surveys. Springer, Cham.

Hart, L. (1989). Describing the affective domain: Saying what we mean. In D. B. McLeod \& V. M. Adams (Eds.), Affect and mathematical problem solving (pp. 37-45). New York: Springer-Verlag. 
Hembree, R. (1990). The nature, effects, and relief of mathematics anxiety. Journal for Research in Mathematics Education, 21, 33-46. doi:10.2307/749455

Hernandez-Martinez, P. \& Pampaka, M. (2017). "I did use to like maths...": emotional changes towards mathematics during secondary school education. In U. Xolocotzin (Ed.), Understanding Emotions in Mathematical Thinking and Learning (pp.187-220). Cambridge: Academic Press.

Hill, F., Mammarella, I. C., Devine, A., Caviola, S., Passolunghi, M. C., \& Szücs, D. (2016). Maths anxiety in primary and secondary school students: Gender differences, developmental changes and anxiety specificity. Learning and Individual Differences, 48, 45-53. doi:10.1016/j.lindif.2016.02.006

Hyde, J. S., Fennema, E., Ryan, M., Frost, L. A., \& Hopp, C. (1990). Gender comparisons of mathematics attitudes and affect: A meta-analysis. Psychology of Women Quarterly, 14, 299-324. doi:10.1111/j.1471-6402.1990.tb00022.x

Jameson, M. M. (2014). Contextual factors related to math anxiety in second-grade children, Journal of Experimental Education, 82, 518-536. doi:10.1080/00220973.2013.813367

Jordan, N. C., Kaplan, D., Ramineni, C., \& Locuniak, M. N. (2009). Early math matters: kindergarten number competence and later mathematics outcomes. Developmental Psychology, 45, 850-8657. doi:10.1037/a0014939

Krinzinger, H., Kaufmann, L., \& Willmes, L. (2009). Math anxiety and math ability in early primary school years. Journal of Psychoeducational Assessment, 27, 206-225. doi:10.1177/0734282908330583

Leder, G. (1985). Measurement of attitude to mathematics. For the Learning of Mathematics, $5,18-22$. 
Leder, G. C., Pehkonen, E., \& Törner, G. (Eds.). (2006). Beliefs: A hidden variable in mathematics education? Springer Science \& Business Media.

Lester, F. K., Garofalo, J., \& Kroll, D. L. (1989). Self-confidence, interest, beliefs, and metacognition: Key influences on problem-solving behavior. In D. B. McLeod \& V. M. Adams (Eds.), Affect and mathematical problem solving: A new perspective (pp. 7588). New York: Springer-Verlag.

Liljedahl, P. G. (2004). The AHA! experience: Mathematical contexts, pedagogical implications. Unpublished doctoral dissertation, Simon Fraser University, Canada. Retrieved from http:/summit.sfu.ca/item/8597

Linnenbrink, E. A. (2006). Emotion research in education: Theoretical and methodological perspectives on the integration of affect, motivation, and cognition. Educational Psychology Review, 18, 307-314. doi:10.1007/s10648-006-9028-x

Ma, X., \& Kishor, N. (1997). Assessing the relationship between attitude toward mathematics and achievement in mathematics: A meta-analysis. Journal for Research in Mathematics Education, 28, 26-47. doi:10.2307/749662

Malmivuori, M. L. (2001). The dynamics of affect, cognition, and social environment in the regulation of personal learning processes: The case of mathematics. Unpublished doctoral dissertation, University of Helsinki, Finland. Retrieved from http://ethesis.helsinki.fi/julkaisut/kas/kas va/vk/malmivuori/

Mandler, G. (1989). Affect and learning: Causes and consequences of emotional interactions. In D. B. McLeod \& V. M. Adams (Eds.), Affect and mathematical problem solving. A new perspective (pp. 3-19). New York: Springer-Verlag.

Mattarella-Micke, A., Mateo, J., Kozak, M. N., Foster, K., \& Beilock, S. (2011). Choke or thrive? The relation between salivary cortisol and math performance depends on 
individual differences in working memory and math-anxiety. Emotion, 11, 1000-1005. doi:10.1037/a0023224

McDonough, A., \& Sullivan, P. (2014). Seeking insights into young children's beliefs about mathematics and learning. Educational Studies in Mathematics, 87, 279-296. doi:10.1007/s10649-014-9565-z

McLeod, D. B. (1988). Affective issues in mathematical problem solving: Some theoretical considerations. Journal for Research in Mathematics Education, 19, 134-141. doi:10.2307/749407

McLeod, D. B. (1989). The role of affect in mathematical problem solving. In D. B. McLeod \& V. M. Adams (Eds.), Affect and mathematical problem solving. A new perspective (pp. 20-36). New York: Springer-Verlag.

McLeod, D. B. (1992). Research on affect in mathematics education: A reconceptualization. In D. A. Grouws (ed.), Handbook of Research on Mathematics Learning and Teaching (pp. 575-596). New York: Macmillan.

McLeod, D. B. (1994). Research on affect and mathematics learning in the JRME: 1970 to the present. Journal for Research in Mathematics Education, 25, 637-647. doi:10.2307/749576

McLeod, D. B., \& Adams, V. M. (1989). Affect and mathematical problem solving: A new perspective. New York: Springer-Verlag.

Op’t Eynde, P., De Corte, E., \& Verschaffel, L. (2006). "Accepting emotional complexity": A socio-constructivist perspective on the role of emotions in the mathematics classroom. Educational Studies in Mathematics, 63, 193-207. doi:10.1007/s10649-0069034-4 
Pekrun, R., Goetz, T., Titz, W., \& Perry, R. P. (2002). Academic emotions in students' selfregulated learning and achievement: A program of qualitative and quantitative research. Educational Psychologist, 37, 91-106. doi:10.1207/S15326985EP3702_4

Ramirez, G., Gunderson, E. A., Levine, S. C., \& Beilock, S. L. (2013). Math anxiety, working memory and math achievement in early elementary school. Journal of Cognition and Development, 14,187-202. doi:10.1080/15248372.2012.664593

Reeve, R., Reynolds, F., Humberstone, J., \& Butterworth, B. (2012). Stability and change in markers of core numerical competencies. Journal of Experimental Psychology: General, 141, 649-666. doi:10.1037/a0027520

Richardson, F., \& Suinn, R. (1972). The mathematics anxiety rating scale: Psychonometric data. Journal of Counseling Psychology, 19, 551-554. doi:10.1037/h0033456

Rittle-Johnson, B., \& Jordan, N. C. (2016). Synthesis of IES-Funded Research on Mathematics: 2002-2013 (NCER 2016-2003), Washington, DC: National Center for Education Research, Institute of Education Sciences, U.S. Department of Education. Retrieved from http://ies.ed.gov/

Schoenfeld, A. H. (1989). Exploration of students' mathematical beliefs and behaviour. Journal for Research in Mathematics Education, 20, 338-355. doi:10.2307/749440

Silver, E. A. (1985). Research on teaching mathematical problem solving: Some underrepresented themes and needed directions. In E. A. Silver (Ed.), Teaching and learning mathematical problem solving: Multiple research perspectives (pp. 247-266). Hillsdale, NJ: Erlbaum.

Vukovic, R. K., Kieffer, M. J., Bailey, S. P., \& Harari R. R. (2013). Mathematics anxiety in young children: concurrent and longitudinal associations with mathematical 
performance. Contemporary Educational Psychology, 38, 1-10.

doi:10.1016/j.cedpsych.2012.09.001

Wigfield, A., \& Meece, J. L. (1988). Math anxiety in elementary and secondary school students. Journal of Educational Psychology, 80, 210-216. doi:10.1037/00220663.80.2.210

Wu, S. S., Barth, M., Amin, H., Malcarne, V., \& Menon, V. (2012). Math anxiety in second and third graders and its relation to mathematics achievement. Frontiers in Psychology, 3, 1-11. doi:10.3389/fpsyg.2012.00162

Wu, S. S., Chen, L., Battista, C., Watts, A. K. S., Willcutt, E. G., \& Menon, V. (2017). Distinct influences of affective and cognitive factors on children's non-verbal and verbal mathematical abilities. Cognition, 166, 118-129. doi:10.1016/j.cognition.2017.05.016

Zan, R., Brown, L., Evans, J., \& Hannula, M. S. (2006). Affect in mathematics education: An introduction. Educational Studies in Mathematics, 63, 113-121. doi:10.1007/s10649006-9028-2 